\title{
LCA Methodology
}

\section{Return on Environment}

\section{An Objective Indicator To Validate Life Cycle Assessments?}

\author{
David Hunkeler ${ }^{1}$ and Gautam Biswas ${ }^{2}$ \\ 'Department of Chemistry, Swiss Federal Institute of Technology, CH-1015 Lausanne, Switzerland \\ 2US-Japan Center for Technology Management, Vanderbilt University, Nashville, TN, 37235, USA
}

Corresponding author: Prof. David Hunkeler, PhD; e-mail: david.hunkeler@epfl.ch

\section{DOI: http://dx.doi.org/10.1065/1ca2000.10.035}

Abstract. The Return on Environment (ROE) is developed, and tested, as an objective indicator to support the results of Life Cycle Assessments. It is based on the observation that a ratio of life cycle costs incurred throughout the extraction, transport, manufacturing, use and disposal stages, to the selling price, appears to scale linearly with a quantitative impact assessment. ROE is therefore a normalization method which permits comparison of new assessments with existing data, even from products with quite different characteristics. It can, alternatively, be applied to estimate either the life cycle cost, or quantify environmental impact, provided the other is known. Like its economic cousin, the return on investment, cases studied typically have ROEs in over the range of $2-20 \%$. ROE is intended as a preliminary estimation method, akin to engineering costing, which has a precision of $\pm 30 \%$. As such, it can be used to rapidly determine if a more detailed cost assessment can be justified and, if so, where the efforts should be oriented. ROE is a measurable life cycle index intended to render LCAs more suitable for decision making. A further benefit that ROE provides is the guidance to a life cycle practitioner, or product development team, to assess if sufficient data has been collected, or if costs and impacts have been over or under-estimated. It has advantages over specific ecoindicators, such as manufacturing energy or waste emissions, which are both product specific and subjective. The Return on Environment also serves as a systematic index for reporting improvements or as a relative environmental rating.

Keywords: EMS; Environmental Management System (EMS); Impact Assessment; ISO; LCIA; life cycle costing; Life Cycle Impact Assessment (LCIA); life cycle management; Return on Environment (ROE); risk assessment

\section{Introduction}

Recent surveys have noted an increase in corporate implementation of life cycle thinking [1]. For example, approximately $40 \%$ of the Fortune 500 firms surveyed employed matrix-based environmental management tools that combine quantitative and qualitative ecometrics. Specific needs for abridged LCA processes which incorporate cradle-tograve costing were also noted, both in North America and Asia [2]. As the ISO 14000 series replaces the previously suggested LCA frameworks [3-6], objective assessment, that aids both public decision making and private sector life cycle management, is becoming the primary focus of international organizations such as SETAC. However, while 'full' LCAs are too costly for routine application, screening introduces subjectivity. Therefore, there is a nced for an objective, yet measurable index that can be employed to establish the validity of an LCA study to which streamlining techniques have been applied. This paper summarizes a series of case studies ${ }^{*}$ that include both life cycle costing and a qualitative risk assessment, and uses them for an empirical study to evaluate the possibility of increasing the objectivity involved in carrying out a new screened, LCA.

\section{LCA Subjectivity}

Subjectivity creeps into any LCA analysis in terms of defining the functional units and the system boundary. These choices can be made in a number of ways. For example, a combination of comparative assertions for similar products can be employed. Alternatively, initial data gathered for various stages of the life cycle can be used to eliminate stages that are projected to have much lower impact [7]. Screening decisions can also be based on expert opinion. Subjectivity is also introduced into the aggregation step of Life Cycle Impact Assessment, where the conclusions drawn are a function of the value system adopted. As these topics have been debated at length in other forums and international committees (e.g. ISO), they will not be discussed in this paper. Herein the authors choose to address the subjectivity in the LCA's conclusions. Specifically, we seek to develop a method to objectively assess the validity of an LCA and which can be used as a tool akin to engineering cost estimation. The latter, with a precision limited to $\pm 30 \%$, is nonetheless utilized routinely as a means to justify further allocation of resources to carry out a more detailed analysis. The 'Return of Environment' which will be presented in this paper is an analogous, first screening approach to rapidly decide if further environmental assessments can be justified.

\footnotetext{
- There are relatively few cases in the open literature where both life cycle costs and a quantitative impact assessment have been presented. This paper, therefore, is presented as a discussion document. Further testing of the hypotheses presented herein will be possible through the examination of various cases and supply chain models for products related to manufacturing, communication transport, textiles, energy and water.
} 


\section{Relation Between Eco-indicators and LCAs}

A significant number of ecoindicators [8], or their synonymous ecometrics [9], have recently been proposed. Ecometrics which include energy use per unit of GDP or per capita, and materials intensity per unit of service (MIPS), are referred to as microecometrics, and global indicators, such as sea level, top soil reserves, average temperature and atmospheric concentrations are macroecometrics. While microecometrics are measurable, and hence attractive from a management and decision making perspective, their link to macroscopic global changes, and hence sustainability, is not established [10]. There is, therefore, no systematic methodology for linking a set of ecometrics to LCA evaluation. This implies that the act of choosing a set of ecometrics for an assessment biases the outcome of the analysis. Furthermore, the function employed for aggregation of ecometrics is stakeholder dependent [11]. A collection of ecometrics, such as those which typically fill corporate environmental reports, cannot substitute for an LCA.

Executives from Fortune 500 firms noted, despite its fundamental advantages, that LCA has thus far not been rapidly integrated by interdisciplinary product teams [1-2]. Criticisms included the unfeasibility of 'full' LCA's for diverse product lines, and the subjectivity which screening introduces which is difficult to justify, or defend, either publicly or through the supply chain. In order to be useful in a corporate decision support framework, LCA methodology needs to evolve into a more objective index that satisfies the following constraints:

1. Be based on quantifiable, investigator independent, systematic, life cycle data.

2. Be scalable, so that the results can be normalized to be representative within and across product lines.

3. Combine environmental, technical and market-based information.

If one then represented the environmental life cycle burden by an overall impact assessment value, and the techno-economic benefits by a cost, expressed over the product life cycle, this might approach the aforementioned three executive requirements to embrace life cycle thinking $[1,2]$. The ratio of the life cycle cost to the quantitative impact assessment can be presented as normalized, although at this point arbitrary, objective index for LCAs:

$$
\text { Nomalized LCA Index }=\frac{\text { Life Cycle Cost }}{\text { Life Cycle Impact Assessment }}
$$

Where the 'life cycle cost' would comprise the economic costs during the resource extraction, transportation, manufacturing, use and disposal stages. For indstries such as agriculture or fishing, where subsidues can be higher than the corporate contribution to CDP, the price mechanism is biased. Under such situations, subsiding-connected selling prices should be employed [12]. Intuitively equation (1) would be satisfactory if a full environmental and cost accounting is performed, since environmentally burdensome products exert a larger life cycle cost, often in a non-use stage. The life cycle cost and the calculated life cycle impact, the latter computed in some arbitrary units such as Ecopoints, would increase proportionally. As an example, consider a situation with low recyclability and, hence a higher disposal related burden. This increases both the life cycle impact and 'cost'. Manufacturing discharges from materials containing TRI chemicals or the increased environmental burden associated with certain mining and pre-processing operations, such as those involved in aluminum production, would also concomitantly cause increases in cost and impact. The relation in equation (1) does not have to be linear, and an exponential scaling factor may be more realistic though additional data is required. The total burden is also a function of the weight or volume of the product and its economic life. In order to utilize equation (1) for a comparison of, for example, pens to refrigerators and automobiles to dairy products, further normalization may be required. To avoid having to introduce product specific factors, which render most existing metrics ungeneralizable [10], it is best that physical attributes, such as mass, and density, not play a role in determining the index. Therefore, as a first approximation we will modify equation (1) by including the economic return, which is the selling price on a per-unit basis, and evaluate if this can be used as a normalization method. The resultant 'reduced life cycle cost' is defined as the life cycle cost divided by the selling price. As a further convenience, we arbitrarily choose a scale of 1-100 to represent the Life Cycle Impact Assessment. The choice of this scale does not make a fundamental difference to the analysis. On the other hand, there are practical advantages, and they are explained subsequently. The normalized life cycle cost can be expressed as:

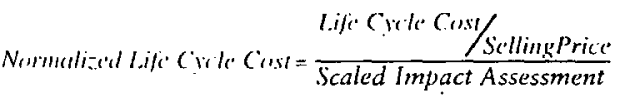

Theoretically, the numerator has a value of unity for a perfectly 'clean' or 'green' product, though the authors' preliminary data indicate that the total life cycle costs will typically be one order of magnitude larger than the product selling price. The denominator has a value of $1-100$, a typical range for semi-quantitative assessments [12]. Therefore, de facto, one would anticipate the normalized life cycle cost to be close to 0.1 for an existing product. Rearranging equation (2) and multiplying by $100 \%$ one obtains an economic return per unit of environment, or 'Return on Environment' (ROE):

$$
R O E=\frac{\text { Life Cylce Cost/Selling Price }}{\text { Scaled Impact Assessment }} \cdot 100 \%
$$

Where the 'productivity per unit of investment' is estimated by the reciprocal of the selling price.

\section{Results}

\subsection{Evaluation of return on environment}

Table 1 summarizes the life cycle cost and impact assessment data for six cases from previous LCA studies we have conducted [13-14], and their ROE calculated using equation (3). It is clear from the two sets of cases that the products present very different environmental burdens. In case of the light bulbs, energy use dominates the life cycle scenario. In contrast, manufacturing and disposal of paints pose 
the greatest health safety and environmental risks for the shelf painting processes. However, the ROE for the various products differ at most by one order of magnitude and are relatively uniformly distributed on a $\log$ scale with three values of approximately $1-2 \%$, one with values on the order of $10 \%$, and two other cases where the ROE is approximately $20 \%$. Overall, the average ROE value is $10.8 \%$ with a median of $8.5 \%$. This paper will evaluate if the return on environment can be used to compare products differing in various characteristics and if it can serve, as a return on investment does as a financial metric, as a relative judgment.

Table 2 shows an ROE calculation for an automobile subcomponent using Global Warming Potentials as the impact category [16]. The ROEs are in the $1-5 \%$ range, consistent with the data in Table 1.
For this case, the firm in question eliminated the alternative with the lowest $\mathrm{ROE}$ (magnesium: $1.1 \% \mathrm{ROE}$ ), which also did not meet the technical specifications based on modules and weight. The second alternative (glass reinforced plastic: $3.9 \%$ ROE) was selected on the basis of technical performance and economic ROE. The third alternative, on ecomaterial based on lignin waste from pulp back liquor (hemp-reinforced rubber: $8.3 \%$ ROE), which had the highest ROE, was further investigated in on RCD program. Therefore, this auto example illustrates the applicability of joint economic and environmental valuations in product design and development prioritization.

Table 3 provides an evaluation of the ROE concept. Consider a case study involving the use of powder coatings to paint the shelving units [13]. The economic cost per unit

Table 1: Summary of the scaled life cycle cost to life cycle impacts for various products

\begin{tabular}{|c|c|c|c|c|}
\hline Product & $\begin{array}{l}\text { Life Cycle Cost* } \\
\text { (\$/unit) }\end{array}$ & $\begin{array}{l}\text { Selling Price } \\
\text { (\$/unit) }\end{array}$ & $\begin{array}{c}\text { Scaled Impact } \\
\text { Assessment as Estimated } \\
\text { from 'Residual Risk' } \\
(0-100)\end{array}$ & $\begin{array}{l}\text { Return on Environment } \\
\qquad(\%)^{\star \star}\end{array}$ \\
\hline $\begin{array}{c}\text { Office Shelf Painted Black } \\
\text { with a Spray Gun using } \\
\text { Organic-Based Paint }\end{array}$ & 0.026 & 0.0258 & 64 & 1.6 \\
\hline $\begin{array}{c}\text { Office Shelf Painted Black } \\
\text { with a Spray Gun using } \\
\text { Organic-Based Paint with } \\
\text { Solvent Recycling }\end{array}$ & 0.035 & 0.0250 & 93 & 1.1 \\
\hline $\begin{array}{c}\text { Office Shelf Painted Black } \\
\text { with a Spray Gun } \\
\text { Using Organic-Based Paint } \\
\text { with Solvent and Sludge } \\
\text { Recycling }\end{array}$ & 0.026 & 0.0258 & 71 & 1.4 \\
\hline Fluorescent Lamp & $12 .(30)$ & 2.01 & 40 & 15 \\
\hline Low Mercury Lamp & 14. $(60)$ & 2.41 & 31 & 20 \\
\hline Very Low Mercury Lamp & 16.(20) & 2.89 & 22 & 26 \\
\hline
\end{tabular}

* For the painting cases, the functional unit is a one pound mass of painted shelf [13], while for the lighting case it is one fluorescent buib [14]

** The ROE is defined as the Selling Price/(Scaled Impact Assessment/Life Cycle Cost)

Table 2: Return on environment - example calcuation using global warming potential as an impact category*

\begin{tabular}{l|c|c|c|c}
\hline Product & $\begin{array}{c}\text { Life Cycle Cost } \\
\text { (DM/Unit) }\end{array}$ & $\begin{array}{c}\text { Global Warming Potential } \\
\text { (kg CO 2 Equivalents) }\end{array}$ & $\begin{array}{c}\text { Scaled Impact Assessment } \\
\text { (0-200) }\end{array}$ & $\begin{array}{c}\text { Return on Environment } \\
\text { (\%) }\end{array}$ \\
\hline $\begin{array}{l}\text { Auto Front Assembly } \\
\text { (Magensium) }\end{array}$ & 52 & 142 & 94 \\
\hline $\begin{array}{l}\text { Auto Front Assembly } \\
\text { (Plastic/Glass) }\end{array}$ & 48 & 40 & 26 \\
\hline $\begin{array}{l}\text { Auto Front Assembly } \\
\text { (Rubber/Hemp) }\end{array}$ & 37 & 19 & 3.9 \\
\hline "Selling price DM 30/unit
\end{tabular}

Table 3: Comparison of estimated and life cycle risk using the proposed ROE and the value reported in the case study

\begin{tabular}{|c|c|c|c|c|}
\hline Product & $\begin{array}{l}\text { Selling Price } \\
\text { (\$/unit) }\end{array}$ & $\begin{array}{c}\text { Scaled Impact } \\
\text { Assessment as Estimated } \\
\text { from 'Residual Risk' } \\
(0-100)\end{array}$ & $\begin{array}{l}\text { Life Cycle Cost from } \\
\text { Case Study } \\
\text { (\$/unit) }\end{array}$ & $\begin{array}{l}\text { Estimated } \\
\text { Life Cycle Cost from ROE } \\
(\$ / \text { unit })^{\star \star}\end{array}$ \\
\hline $\begin{array}{c}\text { Office Shelf Painted Black } \\
\text { with a Spray Gun and } \\
\text { Powder Based Paint }\end{array}$ & 0.0246 & 14 & 0.025 & 0.035 \\
\hline
\end{tabular}


Table 4: Estimation of Life Cycle Cost using the Proposed ROE

\begin{tabular}{|c|c|c|c|c|}
\hline Product & $\begin{array}{l}\text { Selling Price } \\
\text { (\$/unit) }\end{array}$ & $\begin{array}{l}\text { Scaled Impact } \\
\text { Assessments Estimated } \\
\text { from the ERPR* }\end{array}$ & $\begin{array}{c}\text { Ratio of Life Cycle Cost to } \\
\text { Selling Price }\end{array}$ & $\begin{array}{l}\text { Estimated } \\
\text { Life Cycle Cost } \\
\text { (\$/unit) }^{\star *}\end{array}$ \\
\hline Home [16] & 100,000 & 55 & 11 & $1,100,000$ \\
\hline 1950s Automobile [17] & 1,200 & 54 & 11 & 12,960 \\
\hline 1990s Automobile [17] & 20,000 & 32 & 6 & 128,000 \\
\hline \multicolumn{5}{|c|}{ Life Cycle Impact $=100-$ ERPR } \\
\hline \multicolumn{5}{|c|}{ "The ROE was estimated to be $20 \%$ based on previous cases (Table 1 ) } \\
\hline
\end{tabular}

appears in column two, the risk assessment figure (residual risk) appears in column three, and the calculated life cycle cost appears in column four. The last column lists the estimated life cycle cost using equation (3), assuming a ROE of $10 \%$, the mean from the case studies examined in this paper. A $40 \%$ difference between estimated life cycle cost and the value that was quoted in the case study is observed [13]. The 'closeness' of the preliminary estimate to the true value is acceptable, and one can infer that this LCA is consistent with the others performed and, therefore, is not likely to be a gross misrepresentation of the environmental impact and risk. It has been demonstrated that preliminary engineering design and process cost estimates generally also have a precision on the order of $\pm 40 \%$ [15]. Clearly, ten cases (Tables 1 and 2) are insufficient to demonstrate the universality of the ROE concept. However, they do reveal that preliminary estimates of the overall life-cycle cost can be obtained with historic data from unrelated products by assuming an ROE. This is not unlike an economic analysis where the discounted cash flow would be used as a metric to compare alternatives by assuming a discount or interest rate. Therefore, the assumption of a given value for ROE (e.g. 10\%) is an environmental equivalent of assuming a prevailing interest rate (e.g. $4 \%$ ) when making financial comparisons. Neither can be rigorously justified and both are used only to make preliminary assessments.

\subsection{Life cycle costing as a quality of life and sustainability indicator}

The 'environmental responsive product rating' (ERPR), developed by Graedel, uses as an abridged impact assessment measure:

Impact Assessment $\approx 100-E R P R$

Graedel and Allenby have tabulated ERPR values for several products and observed that on a $0-100$ scale, homes [16] and 1950s automobiles [17] have approximately equal impacts of 45 and 46, respectively. Given that ERPR indicates environmental 'friendliness', an application of equations (2) and (3) to the Graedel and Allenby cases results in a ratio of life cycle cost to selling price of 11:1 for both homes and the 1950's vehicles ${ }^{1}$. This implies that the life cycle cost for a middle class US residence is approximately 1.1 million dollars. In contrast, the ERPR of a 1990 s automobile is 68 , implying a ratio of life cycle cost to selling price of 6.4 , and a life cycle cost of $\$ 128,000$ based on an average automobile cost of $\$ 20,000$. These figures are summarized in Table 4 . It is interesting to note that if a dwelling lasts 50 years and an automobile is sold after 4

1 For a home, the factor of 11 is almost identical to the real economic cost of the home to a owner who pays $8 \%$ interest over a 25 -year mortgage (10.68). years, a family owning two cars will incur life cycle costs for their primary transportation needs, i.e. automobiles, which are 2.5 times higher then the life cycle burden of their residence. This statistic was certainly lower at the turn of the century and in the 1950s. Therefore, the ROE analysis permits us to examine not only trends in the style or quality of life, but also provides a crude index of changes in preferences. The ROE is also consistent with service-based ecometrics rather then relying on product or site-based microecometrics [10].

\subsection{Return on environment as a tool to estimate life cycle costs}

The ROE approach presented herein can be used to carry out a preliminary impact assessment provided the economic and life cycle costs can be estimated. The 'materials intensity per unit of service' (MIPS) for automobile manufacturing is know to be approximately 20 , although manufacturing only contributes a $10 \%$ to the overall life cycle burden, with the majority coming from the use and disposal phases. If one assumes that a $1000 \mathrm{~kg}$ automobile lasts for $160,000 \mathrm{~km}$ and consumes fluids at a total rate of $10 \mathrm{U} / 100 \mathrm{~km}$, including oil and lubricants, then the total mass consumption during the use phase, at a fluid density of 0.87 , is $13,920 \mathrm{~kg}$ or 6.96 times the weight of the car. A weighted average MIPS, over the manufacturing and use phases provides a preliminary estimate of the scaled impact equal to 41.3 :

$$
\operatorname{ROE}(10 \%)=\frac{6.96}{\text { Scaled Impact Assessment }} \cdot 100 \%
$$

This value is within $30 \%$ of Graedel's published value of 32 (Table 3). It is important to note that the MIPS and ROE methods are based on a different set of assumptions and, therefore, there is no a priori reason to expect agreement. One is, however, normally satisfied with an order of magnitude similarity between two different estimates (e.g. engineering cost estimation, financial valuations). Therefore, it seems that the ROE can be applied using an estimate of the impact assessment" such as the one obtained by a quantitative risk assessment (Table 1) or ERPR (Table 3), to calculate the life cycle costs. Alternatively, if the life cycle costs are known, or asserted from a material based indicator such as MIPS, a preliminary impact assessment can be performed using an averaged ROE. As was mentioned in the introduction, the ROE method is intended as a pre-streamlining calculation in the Life Cycle Assessment path. It is, therefore, a rapid preliminary estimation tool which can be used to justify further effort, either based on life cycle cost or scaled impact assessment estimates.

\footnotetext{
* Estimation, in this case, refers to a product-based calculation designed to flag
} parts of the analysis which require a more elaborate assessment. 


\section{Discussion}

As additional LCA cost-based case studies are performed, it will be possible to collect a much richer set of ROE information. Once the ROE measure is determined to be statistically valid, it can be used as a preliminary check for future LCA case studies. If the data collected for a particular case study produces a ROE calculation that is two standard deviations above or below the typical value, the LCA analysis may be rejected or the case may be labeled as an outlier. For example, if the calculated ROE for a case study exceeded the upper confidence limit (say, 150\%), the implication is that the product is either extremely environmentally benign or a denominator of Equation (3) has been underestimated. A likely cause is that the risk assessment may not have been comprehensive enough, therefore it should be reevaluated. Conversely, a very low ROE value (e.g., a value of $0.3 \%$ ) is likely to be attributed to incomplete life cycle costing. Therefore, a benefit of ROE calculations is the guidance it provides to the life cycle practitioner to determine if sufficient data has been collected for a particular case study. It is, in this sense, a crude validation tool. One can never guarantee that the real environmental return is not $150 \%$, just as outstanding options may exist in financial assessments. However, such extreme values would cause management to re-evaluate the cost and sales estimates. The same type of re-evaluation decision can be justified environmentally on the basis of ROE.

Calculations which relate the life cycle cost to a quantitative impact assessment can be used in the first step of a life cycle management policy. This could follow a sequence of

1) life cycle thinking,

2) simplified LCA and

3) detailed LCA.

The ROE, as a systematic index, could also be used by firms in reporting improvements in their environmental performance through the life cycle, for example, as a part of the continued certification process involved in ISO 14000. Moreover, the $R O E$ could serve as a kind of environmental rating such as is being sought by several financial institutions and insurance companies [18], which have correlated environmental responsibility with a lower variance in profit fluctuations.

The ROE calculations presented in this paper can be valuable in assessing the state of competition for a hypothetical product, and for make-or-buy decisions [19]. For example, it has been shown that an external acquisition is more likely if the number of rivals expected to develop a similar product is high. Under such circumstances one would expect an evaluation to result in a lower price and higher than usual ROE [20]. Life cycle costing and ROE analyses, in conjunction with 'streamlining' guidelines [7] and thresholds, could also determine which stages, stressors, and impacts have been neglected, or overestimated, in a give case study.

\section{Conclusion}

The comparison of life cycle costs with a quantitative impact assessment provides the ability to utilize a rigorous LCA in a transparent and simple decision making process [21]. The ROE approach, therefore, has advantages over individual ecometrics and ecoindicators which are too specific and lack validation, since it is based on Life Cycle Assessment. Additional cases which contain both cradle-to-grave costing and impact assessments are required to improve the statistics and establish industrial sector, or product specific sub-categories with unique ROE values, akin to sectoral price-to-earnings ratios in corporate valuation. This would permit an unbiased means for conducting simplified Life Cycle Assessments since the validity of reducing data collection could be tested iteratively. Further case studies are under way in the authors' institures.

Acknowledgements. This paper is based on discussions initiated at Ecometrics'98, January 18-20, 1998 in Lausanne, Switzerland. A continuing collaboration with José Maria Hernández Gil is also gratefully acknowledged

\section{References}

[1] Huang E, Hunkeler D (1996): Total Quality Env. Mgt., Winter $1995 / 96,36$

[2] Hunkeler D, Huang E (1996): Environmental Quality Management, Autumn 1996, 86

[3] Heijungs R et al. (1992): Environmental LCA of Products, Guide and Background, NOH Reports 9266 and 9267, Leiden

[4] Lindfors LG (1993): Product Life-Cycle Assessment-Principles and Methodology, Nord 1992:9, Copenhagen; Nordic Council of Ministers, pp 9-23

[5] Society of Environmental Toxicology and Chemistry. (1991): A Technical Framework for Life Cycle Assessment, Washington, D.C.

[6] U.S. Environmental Protection Agency. (1993): EPA/742-R-93003, September

[7] Weitz KA, Sharma A(1998): Env Quality Management 7

[8] DeSimone L, Popoff F (1997): Eco-Efficiency: The Business Link to Sustainable Development. MIT Press, Cambridge, MA

[9] Biswas G, Clift R, Ehrenfeld J, Förster R, Jolliet O, Knöpfel I, Luterbacher U, Russell D, Hunkeler D (1998): Int J LCA 3, 184

[10] Hunkeler, D. (in press): Ecometrics for Life Cycle Management. Int J LCA

[11] Allenby B, Yasui I, Lehni M, Züst R, Hunkeler D (1998): Env. Quality Mgt., Autumn 11

[12] Börlin $M$ (2000): personal communication

[13] Graedel T (1998): Streamlined Life Cycle Assessment, Prentice Hall, Englewood Cliffs, NJ

[14] Biswas G, Kawamura K, Hunkeler D, Dhingra R, Huang E, Curtin $M$ (1998): J. Industrial Ecology 2,127

[15] Haftbaradaran H, Hunkeler D, Biswas G, Kawamura K, Dhingra R, Lanz J, Shahinpoor M, Quinn T (1997): Int J Env Consc Design Manufacturing 6,9

[16] Rebitzer G, Fleischer G, Lichtenvort K, Schiller U (2000): Design for Environment in the Automotive Sector with the Materials Selection Tool euroMat. Proceedings of the Materials Week $2000-$ International Congress on Advanced Materials, Processes and Applications, Muenchen, 25.-28.9.2000 (accepted for publication)

[17] Humphreys KA (1991): Jelen's Cost and Optimization Engineering. McGraw-Hill, New York

[18] Graedel TE (1996): Annu Rev Energy Environ 21, 69

[19] Graedel TE, Allenby BR, Comie PR (1995): Matrix Approaches to Abridged Life Cycle Assessment. Environ Sci 29, 134A

[20] Lehni M (1998): State-of-Play Report of the World Business Council for Sustainable Development's Project on Eco-Efficiency Metrics and Reporting, Geneva, Switzerland

[21] Kurokawa S (1997): IEEE Transactions on Engineering Management. 44, 124

[22] Meyer GE (1997): Environmental Quality Management. 7, 81

[23] Larson TJ, Brown HJ (1997): Designing Metrics that Fit: Rethinking Corporate Environmental Performance Systems. Env. Quality Management. 81, Spring

Received: January 26th, 2000 Accepted: May 27th, 2000 Online-First: November 24th, 2000 